\title{
Estudio arqueométrico del soporte marmóreo de una escultura de Livia hallada en la ciudad romana de Asido (Medina Sidonia, Cádiz)
}

\author{
Esther Ontiveros, José Beltrán Fortes, María Luisa Loza
}

\begin{abstract}
Resumen: Este artículo muestra el estudio arqueométrico realizado sobre una escultura de Livia, hallada en la ciudad romana de Asido (actual Medina Sidonia, Cádiz, España), conservada en dos partes disociadas (cabeza y cuerpo), con objeto de ampliar el conocimiento sobre el hallazgo escultórico localizado actualmente en el museo de Cádiz. Estas piezas elaboradas en mármoles blancos han sido analizadas desde el punto de vista mineralógico-petrográfico y geoquímico y posteriormente, se ha llevado a cabo un estudio comparativo con material de canteras explotadas y comercializadas en el sur de Hispania, así como con otros mármoles foráneos de amplio uso en época romana en la provincia Baetica. Los resultados analíticos indican que ambas piezas, aunque con rasgos texturales y composicionales diferentes, pueden provenir de una misma cantera. Los rasgos petrográficos son coincidentes con otras variedades tanto locales como foráneas, pero sus componentes químicos mayoritarios y trazas han permitido establecer como origen más probable las canteras de Almadén de la Plata (Sevilla, España). El mármol de la cabeza de tamaño de grano grueso, aspecto translúcido y sacaroideo presenta contenido en $\mathrm{Cl}$ y $\mathrm{Zn}$, Zr y La; que permiten atribuir como origen a una variedad de mármol blanco calcítico translucido con venas rosáceas, típico de Almadén de la Plata. Por otra parte los contenidos similares en $\mathrm{MgO}, \mathrm{Fe}_{2} \mathrm{O}_{3}$, Ba y trazas de Th observados en el mármol del cuerpo, indican su correlación con una variedad de mármol blanco de tamaño de grano más heterogéneo con venas grisáceas y textura bandeada, donde se alternan bandas de grano medio a grueso con bandas de grano más fino, también típico de estas antiguas canteras. Este estudio también pone de manifiesto la cuidadosa selección del material que se usaba en la elaboración de las cabezas-retratos de las esculturas romanas.
\end{abstract}

Palabras clave: arqueometría, marmorea, escultura romana, análisis petrográfico, difracción de rayos X, fluorescencia de rayos X

\section{Analytical study of the marble support of a Livia sculpture found in the roman city of Asido (Medina Sidonia, Cádiz)}

\begin{abstract}
This paper shows the archaeometric study carried out on a sculpture of Livia, found in the city of Asido (Medina Sidonia, Cádiz, Spain), conserved in two dissociated parts (head and body), in order to expand the knowledge about the sculptural find, currently located in the museum of Cádiz. These pieces made of white marbles have been analyzed from the mineralogicalpetrographic and geochemical point of view and later, a comparative study has been carried out with material from quarries exploited and marketed in southern Hispania, as well as with other foreign marbles widely used in Roman times in the Baetica province. The analytical results indicate that both pieces, although with different textural and compositional features, may come from the same quarry. The petrographic features coincide with other local and foreign varieties, but their major and traces chemical components allowed to establish the quarries of Almadén de la Plata (Seville, Spain) as the most probable origin. The marble of the head of coarse grain size, translucent and saccharoid appearance presents content of $\mathrm{Cl}$ y $\mathrm{Zn}, \mathrm{Zr}$ and La; that allow to attribute as origin to a variety of translucent calcitic white marble with pinkish veins typical from Almadén de la Plata. On the other hand, the similar contents in $\mathrm{MgO}, \mathrm{Fe}_{2} \mathrm{O}_{3^{\prime}} \mathrm{Ba}$ and traces of Th observed in the marble of the body, indicate its correlation with a variety of white marble of more heterogeneous grain size with grayish veins and banded texture, where bands of medium to coarse grain with finer grain bands, also typical of these old quarries. This study also shows the careful selection of the material that was used in the elaboration of the heads-portraits of the Roman sculptures.
\end{abstract}




\section{Estudo arqueométrico do suporte de mármore de uma escultura de Lívia encontrada na cidade romana de Asido (Medina Sidonia, Cádiz)}

Resumo: Este artigo mostra o estudo arqueométrico realizado sobre uma escultura de Lívia, encontrada na cidade romana de Asido (atual Medina Sidonia, Cádiz, Espanha), conservada em duas partes dissociadas (cabeça e corpo), a fim de ampliar o conhecimento sobre o achado escultórico atualmente localizado no museu de Cádiz, que contribui para a sua restituição completa e para melhorar a sua musealização. Essas peças elaboradas em mármores brancos foram analisadas do ponto de vista mineralógico-petrográfico e geoquímico e, posteriormente foi realizado um estudo comparativo com materiais de pedreiras exploradas e comercializadas no sul da Hispânia, bem como com outros mármores estrangeiros de amplo uso na época romana na província de Baetica. Os resultados analíticos indicam que ambas as peças, embora com características texturais e composicionais diferentes, podem ser provenientes da mesma pedreira. As características petrográficas coincidem com outras variedades locais e estrangeiras, mas os seus componentes químicos maioritários e vestigiais permitiram estabelecer as pedreiras de Almadén de la Plata (Sevilha, Espanha) como a origem mais provável. O mármore da cabeça, de granulometria grossa, aspeto translúcido e sacarídeo apresenta teores de $\mathrm{Cl}$ e Zn, Zr e La que permitem atribuir como origem uma variedade de mármore branco calcítico translúcido com veios rosados, típico de Almadén de la Plata. Por outro lado, os teores semelhantes de $\mathrm{MgO}, \mathrm{Fe}_{2} \mathrm{O}_{3^{\prime}}$ Ba e vestígios de Th observados no mármore do corpo, indicam a sua correlação com uma variedade de mármore branco de granulometria mais heterogénea com veios acinzentados e textura em faixas, com faixas de grão médio a grosso alternam com bandas de grão mais fino, também típicas destas pedreiras antigas. Este estudo mostra também a seleção criteriosa do material que foi utilizado na elaboração dos cabeçasretratos das esculturas romanas.

Palavras-chave: Arqueometria, mármore, escultura, análise petrográfica, difração de raios $\mathrm{X}$, fluorescência de raios $\mathrm{X}$

\section{Introducción}

Ha sido objeto de este trabajo determinar la procedencia del mármol empleado en la elaboración de las dos piezas - cuerpo y cabeza - de una estatua romana de Livia hallada en la ciudad antigua de Asido (Medina Sidonia, prov. Cádiz) (Beltrán-Loza 2018) con objeto de ampliar el conocimiento sobre esta escultura. La cabeza se ha elaborado en un mármol blanco de grano grueso con finas venas rosáceas, de aspecto translúcido y sacaroideo y con un desarrollo importante de manchas rojizas. Por otra parte, el cuerpo de la estatua corresponde a un mármol blanco de aspecto más opaco, tamaño de grano más heterogéneo y con la presencia de un bandeado de aspecto grisáceo [Figura 1]. La observación macroscopia de los mármoles es esencial antes de aplicar una metodología analítica basada en multi-métodos (Antonelli \& Lazzarini 2015), estas características macroscópicas previas han sido esenciales para el desarrollo de este trabajo.

En la investigación arqueológica conocer la procedencia de los materiales pétreos utilizado en la elaboración de las piezas arqueológicas es de gran importancia, ya que puede proporcionarnos información sobre los talleres donde se elaboraron y su ámbito de comercialización. Son los estudios arqueométricos sobre estos soportes pétreos, en combinación con los estudios de las canteras explotados en época romana en este sector y áreas de influencia, la clave para conocer su procedencia de una forma más fiable.

La metodología empleada en este trabajo se basa en el estudio analítico del mármol utilizado para la elaboración de estas piezas, y su posterior comparación con muestras de canteras explotadas y comercializadas en época romana, en el ámbito de la Bética romana. Aunque la dificultad para identificar la procedencia de los mármoles de uso arqueológico ha sido puesta de manifiesto

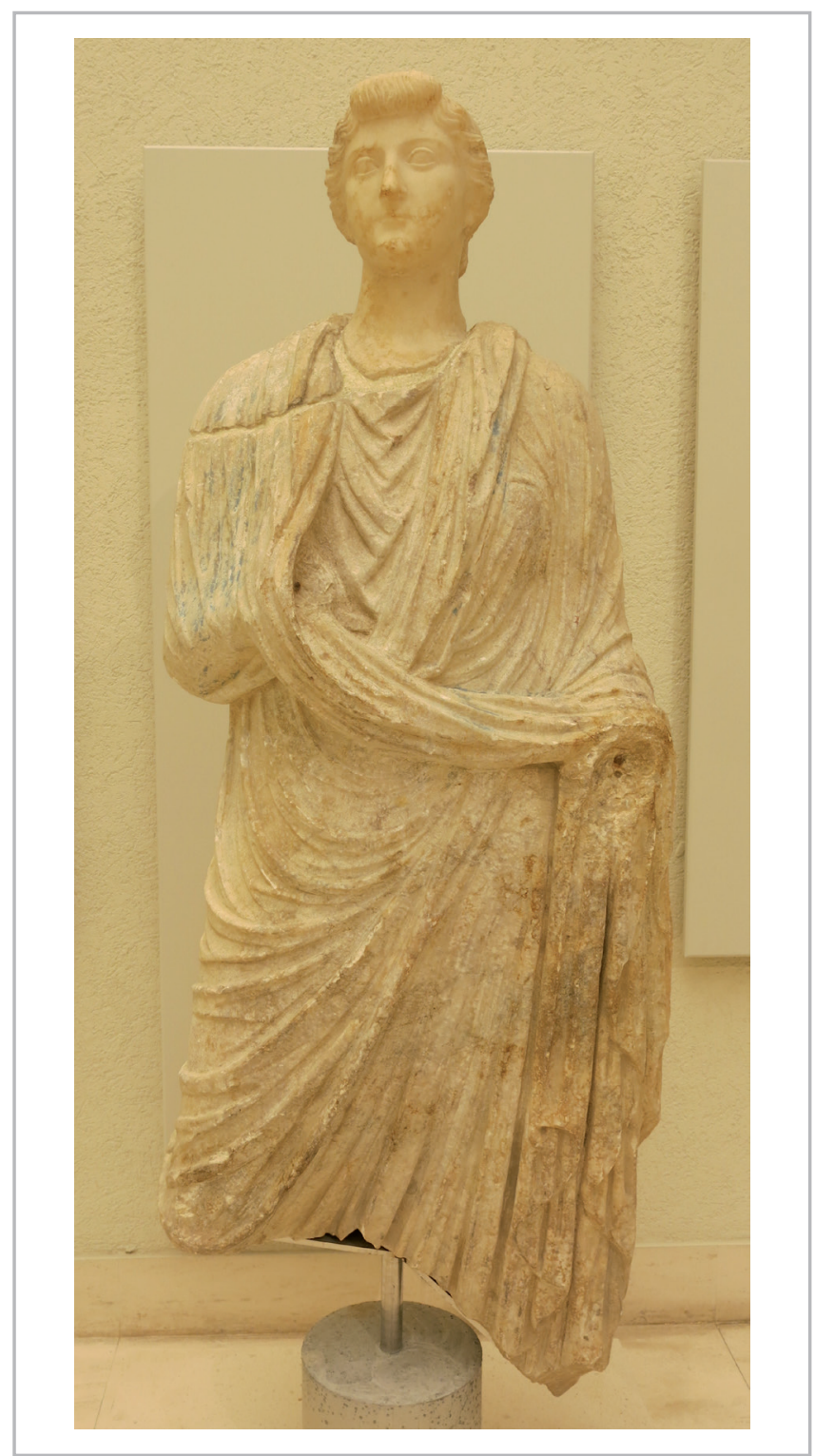

Figura 1.- Escultura de la Livia de Asido (Medina Sidonia, Cádiz). Museo de Cádiz. Foto: autores. 
en numerosos trabajos de investigación, bien por la limitación de las muestras de cantera analizadas, tamaño de las muestras arqueológicas o por la diversidad de métodos usados para su caracterización (Lapuente et al. 2014), el análisis multi-método amplio de los frentes de cantera junto con los criterios arqueológicos se proponen como la metodología más adecuada en esta línea de investigación (Antonelli et al. 2014; Blanc et al. 2020).

En este trabajo las muestras arqueológicas se han caracterizado desde el punto de vista petrográfico, mineralógico y geoquímico y su posterior comparación con material de canteras localizadas en el Sur de Hispania, como de Almadén de la Plata (Sevilla, España) y Borba (Anticlinal de Estremoz, Portugal). Por otra parte se ha llevado a cabo un estudio comparativo con material de procedencia foránea como Luni (Italia), Naxos y Paros (Grecia); en este caso se ha utilizado material procedente de piezas arqueológicas halladas en Astigi, Italica, Baelo Claudia, Medina Sidonia, Hispalis entre otras, todas localizadas en el sector occidental de la provincia romana Baetica.

El material de canteras de referencia usado en este trabajo forma parte de la litoteca, elaborada en el Laboratorio de Geología del Instituto Andaluz del Patrimonio Histórico (a partir de ahora IAPH) en colaboración con el Departamento de Prehistoria y Arqueología de la Universidad de Sevilla, en el marco de varios proyectos de investigación financiados por el Ministerio de Ciencia, Innovación y Universidades del Gobierno de España. Esta base de datos cuenta con un inventario amplio de muestras pétreas, no solo de canteras romanas (más de 100 muestras de referencia) sino de materiales arqueológicos pertenecientes a yacimientos situados en la provincia Hispania Ulterior Baetica. Esta base de datos incluye información sobre las características microtexturales, mineralógicas y geoquímicas obtenidas con los mismos métodos, siendo así más fiables desde el punto de vista comparativo. Estudios previos sobre estas canteras antiguas han puesto de manifiesto las diferencias texturales y composicionales que pueden presentar estas rocas en los afloramientos geológicos, incluso a escala centimétrica (Ontiveros 2008: 365-376; Ontiveros et al. 2012: 407-418; Taylor 2015), pero que resultan de utilidad a la hora de identificar posibles variedades texturales que se pueden encontrar en materiales arqueológicos, como es en este caso de estudio.

Dentro de los métodos analíticos seleccionados la petrografía constituye una técnica fundamental para la diferenciación de materiales pétreos en general. Para el caso concreto de los mármoles, su caracterización petrográfica viene dada por su naturaleza mineralógica, el tamaño máximo de grano (MGS), el tipo de contacto entre ellos (GBS), su análisis microtextural, así como por la naturaleza de los minerales accesorios (Capedri \& Ventuselli 2004; Capedri et al. 2004; Attanasio et al. 2013). Por otra parte, la composición mineralógica y geoquímica es de gran ayuda para su diferenciación (Cramer et al. 2010:
143-160; Ebert et al. 2010: 209-228). La composición de los carbonatos, como son su contenido en calcita o dolomita, resulta un criterio fundamental a la hora de identificar un mármol (Lazarini et al. 1980; Lapuente 1995). Dentro de la composición geoquímica el contenido en $\mathrm{MgO}, \mathrm{Fe2O} 3$, $\mathrm{Sr}, \mathrm{MnO}, \mathrm{Ba}$ y $\mathrm{CaO}$ es de interés al formar parte de la red cristalina de los carbonatos. El Sr ha mostrado tener un alto potencial discriminatorio en diferentes materiales de mármol (Cramer et al. 2010: 143-160). No obstante, estudios arqueométricos previos sobre mármoles antiguos ponen de manifiesto que la huella digital única, ya sea mediante petrografía o análisis geoquímico, no es posible (Moens et al. 1988: 243-250) y además la técnica empleada puede aportar resultados variables (Brilli et al. 2020), de ahí que este método propuesto en este trabajo para el caso de estudios arqueométricos sobre piezas arqueológicas de provincia Baetica resulte de interés para el avance en la investigación arqueológica de este sector del sur de Hispania.

\section{Contextualización arqueológica de la escultura}

En mayo de 1960 durante los movimientos de tierra realizados en el Cerro del Castillo de Medina Sidonia, la antigua Asido, con motivo de la construcción de un depósito de aguas para abastecer al municipio, se descubrió un conjunto de restos escultóricos, en el que destacaban tres retratos, dos de ellos masculinos, identificados con Germánico y Druso el Menor, y uno femenino, que correspondía a una representación de Livia la esposa de Augusto, así como parte de una escultura, femenina, casi completa, amén de otros fragmentos escultóricos menores (Beltrán et al. 2018).

Los tres retratos se expusieron en el Museo de Cádiz, en donde ingresaron las esculturas, pero la estatua del cuerpo femenino permaneció desde entonces en los almacenes del museo, inédita. Hace unos años se realizó un primer estudio de la escultura donde se estableció una correlación entre el retrato de Livia y el cuerpo femenino, en función de las dimensiones y el tipo escultórico documentado. El retrato ( $n^{\circ}$ de inventario CE07209) y el cuerpo de Livia ( $n^{\circ}$ de inventario CE07208) presentan de forma conjunta unas dimensiones conservadas de 2,02 m de altura, 0,64 m de anchura y 0,41 $\mathrm{m}$ de grosor; por tanto son superiores al tamaño natural, si tenemos en cuenta que le falta la parte inferior del cuerpo, por debajo de las rodillas (Beltrán \& Loza 2015).

El retrato presenta unos rasgos fisonómicos y un tipo de peinado que lo identifican como una representación de la emperatriz Livia, que sigue el modelo de una pieza procedente de El Fayum, un tipo muy popular del que se conocen un buen número de copias en el mundo romano (Beltrán, Loza \& Montañés 2018: 61-64, n 6). El cuerpo, que presenta una oquedad en su parte superior realizada para la inserción del retrato, y donde encaja de manera adecuada el retrato de Livia, se viste con túnica y manto 
sobre los hombros, cayendo uno de sus extremos desde la mano izquierda hasta el suelo en un haz de pliegues; esa misma disposición del vestido la presentan otras esculturas de la emperatriz, como una conservada en el Museo Nazionale Romano (para el cuerpo: Scholz 1998: 35-36 no St. 8; para el retrato, Fittschen \& Zanker 1983: $\left.1-2, n^{\circ} 1\right)$. No obstante, será en un ambiente provincial, en la ciudad de Narona, en la antigua Iliria, donde se descubrió una escultura de Livia del denominado tipo Oxford-Opuzen, que formó parte de un templo dedicado al culto imperial, el Augusteum de la ciudad. Es esta representación de Livia la que presenta una mayor similitud con la que estudiamos aquí. A ese ejemplar de Narona se le ha dado una datación diferente para la elaboración del cuerpo, fechado en los momentos finales del reinado de Augusto, y para la elaboración del retrato, que se considera algo más tardío, en los inicios de época tiberiana. Como es habitual en este tipo de esculturas, la cabeza y el cuerpo están esculpidos en mármoles diferentes, siendo de mayor calidad la primera, trabajada en mármol de Paros, mientras que el cuerpo es de menor calidad de ejecución y se ha elaborado en mármol de las canteras del Pentélico (Marín et al. 2004: 76-86 y 340344).

En Medina Sidonia, la fecha de elaboración del retrato de Livia es controvertida; frente a ciertos investigadores que la sitúan-como el caso de Narona-en los inicios del reinado de Tiberio (León 2001: 322-325, n 99), otros la consideran de época tardoaugustea (Garriguet 2004: 68-70). La datación se ha establecido en función de su analogía con los retratos de Germánico y Druso el Menor y la relación entre ellos, formando parte de un mismo ciclo escultórico de época julio-claudia en honor a la Domus Augusta, bien en los últimos años del principado augusteo, o bien en los inicios del reinado de Tiberio (Beltrán \& Loza 2018: 63).

El estado semiacabado, que presentan tanto el retrato como el cuerpo de la escultura de Livia de Asido, proyectada para una visión frontal, que deja la parte posterior sin elaborar, es un detalle propio de los talleres béticos que trabajaron en época julio-claudia en esa ciudad romana; ello supone una colocación para ser vista exclusivamente de frente (Beltrán \& Loza 2018: 64). Este criterio arqueológico apoya la posible procedencia local tanto del mármol como del taller donde se elaboró. Ha sido objetivo de este estudio arqueométrico confirmar el posible origen local de este mármol en base a criterios analíticos y poder corroborar como ocurre en otras áreas del imperio romano la selección de un mármol de mayor calidad para la elaboración del retrato.

\section{Material y métodos}

Las muestras analizadas se extrajeron de zonas no visibles y fueron de pequeño tamaño; su descripción se muestra en la Tabla 1 y su observación visual en detalle del mármol en la Figura 2.

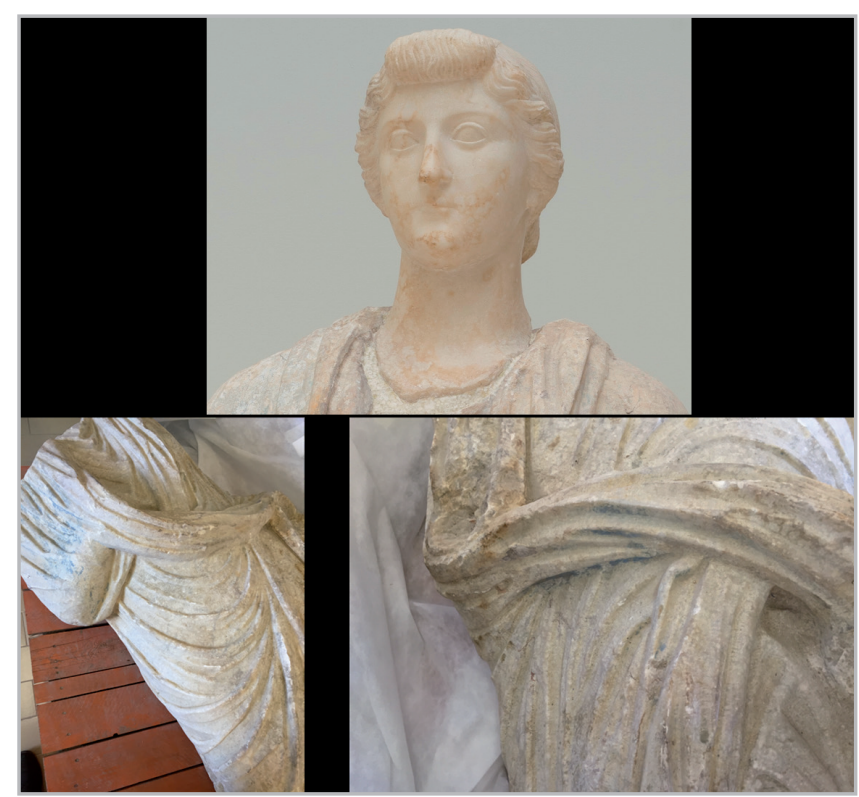

Figura 2.- Detalles de la escultura (retrato y cuerpo). Fotos: autores.

Tabla 1.- Descripción de las muestras extraídas de la escultura de Livia (Museo de Cádiz).

\begin{tabular}{|l|l|l|}
\hline Muestras & Ubicación & Descripción Visual \\
\hline MSID-29 & Cabeza Livia & $\begin{array}{l}\text { Mármol blanco de grano } \\
\text { grueso, aspecto translúcido } \\
\text { y sacaroideo. Desarrollo } \\
\text { de venas rojizas, pátinas y } \\
\text { manchas rojizas. }\end{array}$ \\
\hline MSID-30 & Cuerpo Livia & $\begin{array}{l}\text { Mármol blanco de grano } \\
\text { medio y aspecto opaco. La } \\
\text { alteración superficial y restos } \\
\text { de policromía impiden ver la } \\
\text { presencia de posibles vetas } \\
\text { grisáceas o rosáceas que se } \\
\text { intuyen tras la observación } \\
\text { detallada de la pieza } \\
\text { arqueológica. }\end{array}$ \\
\hline
\end{tabular}

La composición mineralógica de los materiales se determinó mediante difracción de rayos $X(D R X)$; utilizando un difractómetro D8I 90, BRUKER (CITIUS, Universidad de Sevilla) con tubo de ánodo de cobre, método semicuantitativo estándar $\left(\Delta 2 \theta=3-70^{\circ}\right.$; paso $=0,015^{\circ}$; $\mathrm{t}=0,1 \mathrm{~s}$; condiciones del tubo: $40 \mathrm{kV}$ y $30 \mathrm{~mA}$; rendija de divergencia: $0,5^{\circ}$ fijo, giro $30 \mathrm{rpm}$ ); y filtro níquel en el tubo. Duración: $6 \mathrm{~min}$. $54 \mathrm{~s}$. El análisis químico de elementos principales y traza se llevó a cabo utilizando el método de minitrazas de fluorescencia de rayos, $X$ Phillips (FRX) y un espectrómetro PANalytical AXIOS Rh (CITIUS, Universidad de Sevilla). Las secciones delgadas se pulieron hasta un grosor estándar de $30 \mu \mathrm{m}$, se cubrieron con un cubre objetos de vidrio y se examinaron con un microscopio petrográfico Leica, DMLP y cámara con sistema de captura de imágenes digitales Leica DFC 280 (IAPH). 
Esta metodología se aplicó a las muestras de referencia procedentes de las canteras y piezas arqueológicas usadas en el estudio comparativo (Base de datos y Litoteca del IAPH). Además se establecen correlaciones con datos recogidos en la bibliografía científica (Álvarez et al. 2009, Taelman et al. 2013: 2227-36; Antonelli \& Lapuente 2015: 405-425; Belfiore 2016: 236-249; Poretti 2016).

\section{Resultados y Discusión}

\section{—Análisis mineralógico-petrográfico}

El análisis mineralógico indica que en los dos casos el mármol es calcítico y como minerales accesorios se detecta en la muestra MSD-30 (cuerpo de Livia) cuarzo. La observación a través del microscopio petrográfico muestra diferencias desde el punto de vista microtextural que pasamos a describir a continuación [ver Tabla 2].

El mármol utilizado en la elaboración de la cabeza de la escultura de Livia corresponde a un mármol muy puro compuesto mayoritariamente por blastos de calcita de textura granoblástica-heteroblástica de tipo poligonal y en mosaico, con desarrollo importante de puntos triples. Dado el tamaño del fragmento analizado, la observación petrográfica no permite tener una visión global de la textura, por lo que es posible que esta muestra presente igualmente textura en mortero. El tamaño de grano de los blastos de calcita va de medio a grueso (> 1mm MGS < 2,5 mm) con cierta orientación, y es frecuente observar un maclado fino y desarrollo de microfisuras, indicando fases de deformación en condiciones frágiles. El contacto de los granos es mayoritariamente de tipo penetrativo y suturado. Como accesorios se observan granos de cuarzo, feldespatos y óxi-hidróxidos de hierro dispersos en la roca.

El mármol utilizado en la elaboración del cuerpo de la escultura de Livia, corresponde igualmente a un mármol calcítico, con pequeños blastos de cuarzo de tamaño micra.
Presenta igualmente textura granoblástica heterogranular y en mosaico con importante desarrollo de puntos tiples, pero en este caso los blastos de calcita son de tamaño fino (MGS< $0.5 \mathrm{~mm}$ ). No se observa orientación de los blastos y es frecuente observar desarrollo de maclas rectas y gruesas indicando una fase de crecimiento en condiciones estáticas. Los contactos son mayoritariamente rectos y a veces curvos. Como accesorios se observan granos de cuarzo, magnetita y óxi-hidróxidos de Fe, dispersos en la roca o como en el caso de cuarzo formando aglomeraciones.

El rango de tamaño máximo (MGS), su aspecto translucido y la casi ausencia de minerales accesorios que presenta la muestra MSD-29, hace atribuirle como posible origen al mármol de Paros (Gorgoni et al. 2002; Capadri et al. 2004) o naxos, rasgos texturales que coinciden con la variedad blanco translucido de textura gruesa de Almadén de la Plata (Base de Datos Arqueodata; Ontiveros 2008; Ontiveros et al. 2012; Taylor 2015); aunque existen variedades similares en el Anticlinal de Estremoz (Portugal), se descarta esta variedad porque las canteras antiguas de este sector se caracterizan por presentar mármoles con variedades de grano fino (Taelman et al. 2013). El aspecto petrográfico que presentan las muestras de referencia se puede ver en la Tabla 3.

El mármol de Paros procedente del área del Egeo presenta dos variedades, la más valorada en la antigüedad fue la llamada variedad lychnites. La principal cantera de mármol de lychnites se encuentra a aproximadamente 5.5 kilómetros de Parikia, en las laderas del Monte Marpessa, y su característica principal, además del color blanco, es ser casi completamente desprovisto de impurezas y parcialmente transparente. Esta variedad estaba disponible generalmente solo en bloques pequeños, dadas las dificultades asociadas con la actividad minera de extracción (subterránea). Esta es la razón por la cual la mayoría de las estatuas de mármol romano tenían solo la cabeza hecha con este tipo de mármol (Pensabene 2002; Attanasio 2003). Esto no ha llevado a pensar en un primer momento la posibilidad de que la cabeza fuese elaborada con este tipo de mármol u otra variedad foránea.

Tabla 2.- Observación petrográfica de las muestras de mármol de la escultura de Livia.

\begin{tabular}{|c|c|c|}
\hline Muestras & Rasgos microtexturales observados a través del microscopio petrográfico & Descripción \\
\hline $\begin{array}{c}\text { MSID-29 } \\
\text { Cabeza }\end{array}$ & 8 & $\begin{array}{l}\text { Se observan blastos de calcita } \\
\text { con cierta orientación de tamaño } \\
\text { medio a grueso ( }>1 \mathrm{~mm} \text { MGS }< \\
2 \mathrm{~mm} \text { ) y textura heteroblástica } \\
\text { poligonal o en mortero. Contactos } \\
\text { penetrativo y suturado con } \\
\text { presencia de microfisuras. }\end{array}$ \\
\hline $\begin{array}{c}\text { MSID-30 } \\
\text { Cuerpo }\end{array}$ & n & $\begin{array}{c}\text { Se observan blastos de calcita no } \\
\text { orientada de tamaño fino (MGS< } \\
0.5 \mathrm{~mm} \text { ) y textura heteroblástica } \\
\text { poligonal. Contactos rectos y a } \\
\text { veces curvos, presencia de granos } \\
\text { de cuarzo. }\end{array}$ \\
\hline
\end{tabular}


Tabla 3.- Observación petrográfica de las muestras de las canteras de Paros, Naxos y Almadén de la Plata (Arqueodata, IAPH).

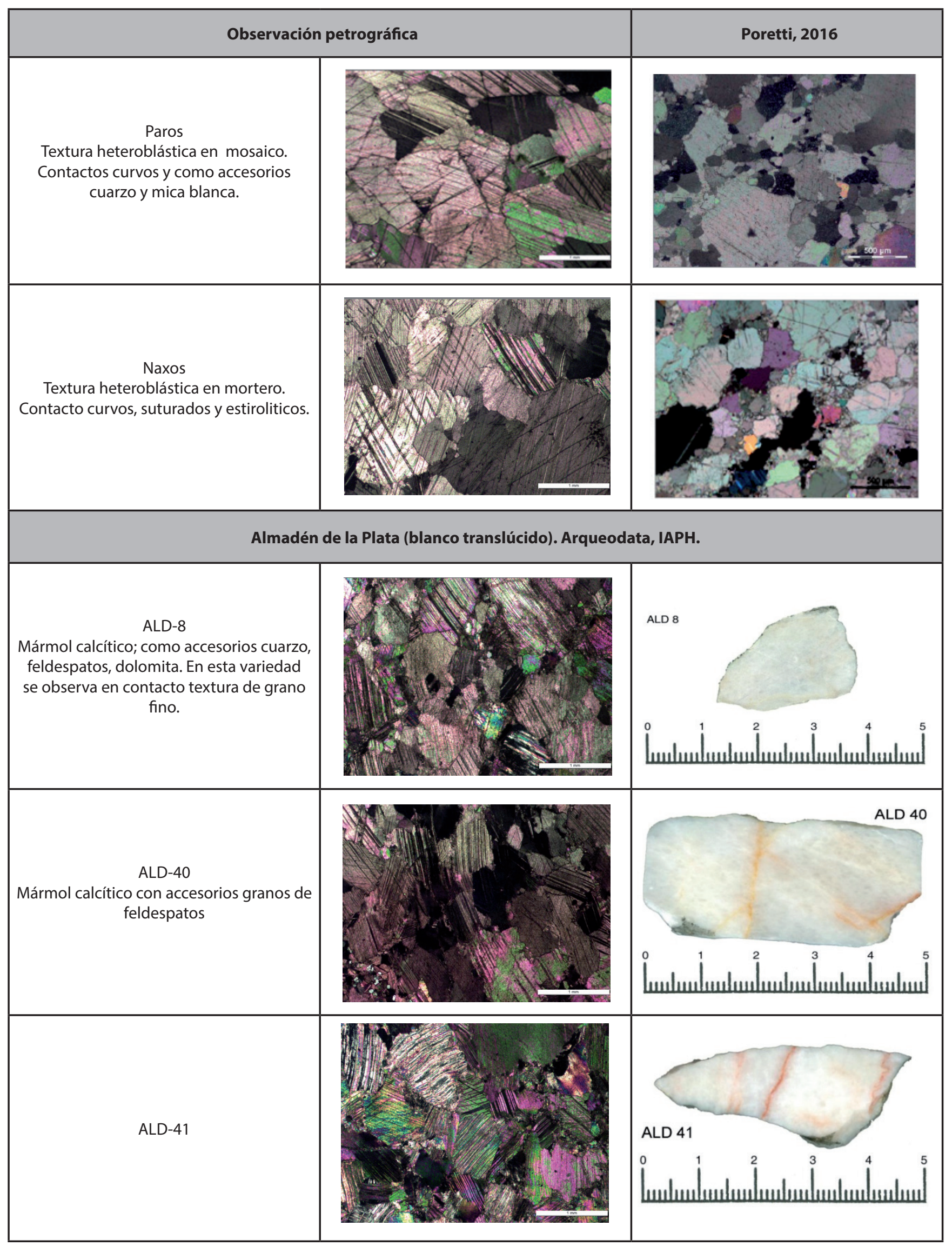


Tabla 4.- Observación petrográfica del mármol de las canteras de Luni, Borba y Almadén de la Plata.

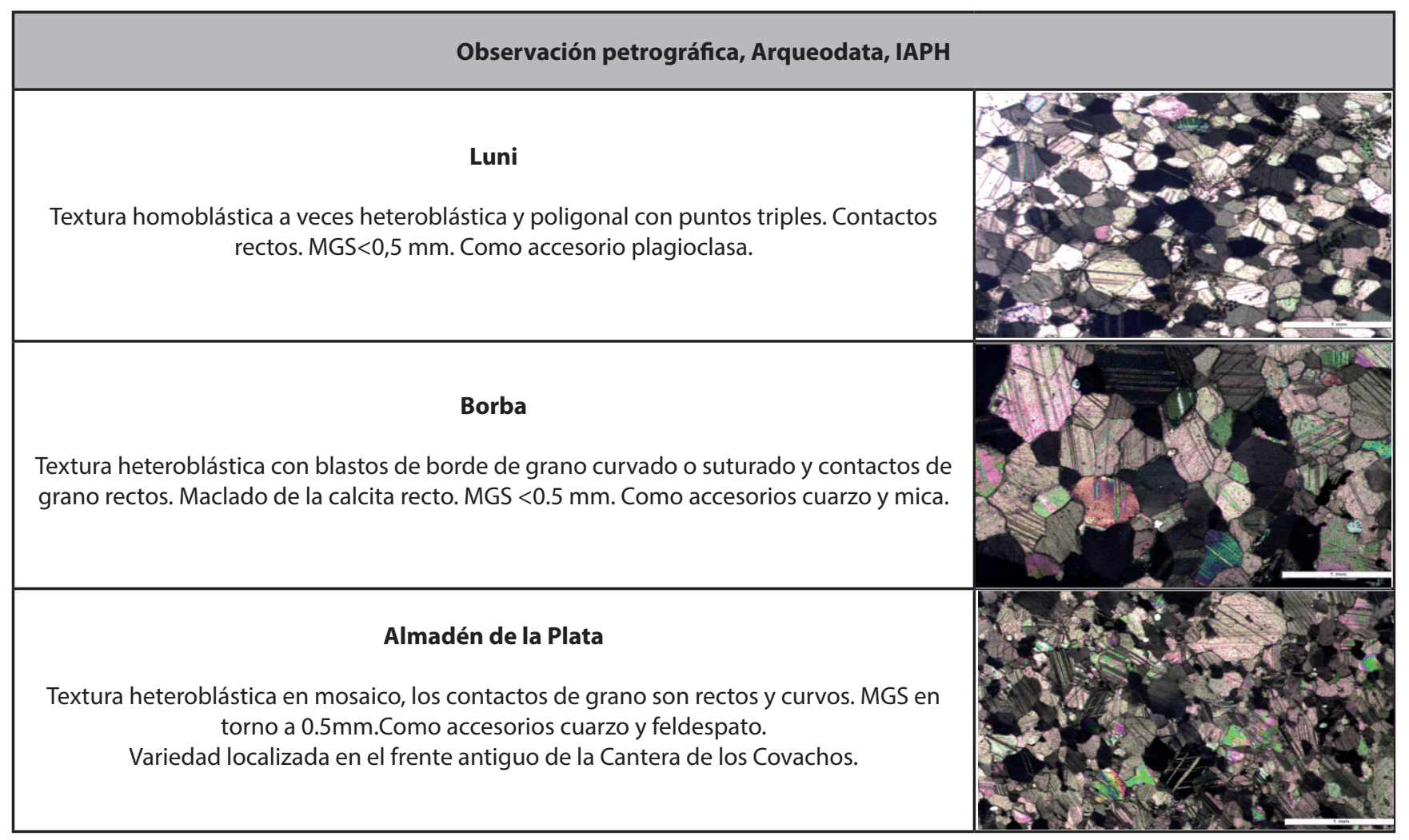

La observación petrográfica del mármol del cuerpo de Livia, tamaño de grano fino y textura homoblástica y en mosaico ha hecho atribuirle tres posibles orígenes: mármol de Almadén de la Plata (variedad poco frecuente en estas canteras, que aparece asociada a otras variedades texturales más características de este tipo de mármol), mármol Luni (italiano) o mármol de Borba (portugués) (Base de Datos Arqueodata IAPH; Ontiveros 2008; Ontiveros et al. 2012; Taylor 2015). El aspecto petrográfico que presentan las muestras de referencia se puede ver en la Tabla 4. Resulta de interés destacar que para el caso del mármol portugués las variedades de grano más fino corresponden a las localizadas en las canteras romanas de Vigária y Lagoa (MGS $<1 \mathrm{~mm}$ ) (Taelman et al. 2013).

\section{- Análisis Geoquímico}

La composición de los elementos mayoritarios de las muestras arqueológicas se puede observar en la Tabla 5. Los datos indican que se trata, en los dos casos, de un mármol puro con contenidos variables en elementos mayoritarios en un margen estrecho, atribuibles la mayor parte a la composición de los minerales accesorios e impurezas. Es claramente visible la mayor pureza del mármol empleado en la elaboración de la cabeza y su mayor contenido en MgO. Las mayores diferencias se observan en la muestra MSD-30 (cuerpo de Livia) con altos proporción en $\mathrm{SiO}_{2}$, que se explica por la presencia de granos de cuarzo detectada por difracción de rayos $X$ y observados a través del microscopio petrográfico. Los contenidos en $\mathrm{Fe}_{2} \mathrm{O}_{3}$ se pueden atribuir a la presencia de óxi-hidróxidos de Fe que se han observado difuminados por el mármol o localizados en venas rojizas y en parte al desarrollo de pátinas rojizas que se observan claramente en la cara de Livia (MSD-29); para el resto de los elementos no se observan diferencias de interés [ver Figura 3a]. Estas variaciones pueden estar en el rango de variabilidad que se puede observar en un mismo tipo de mármol; en consecuencia, no son variaciones que puedan establecer diferencias en cuanto a su origen (Ontiveros et al. 2012: 407-418, Taylor 2015).

La composición de los elementos traza de las distintas muestras se puede observar en la Tabla 6. Los datos indican que la muestra MSD-30 (cuerpo de Livia) presenta mayores contenidos en Ba y Sr. Por el contrario la muestra MSD-29 (cabeza de Livia) presenta mayores contenidos en $\mathrm{Cl}$ y se observan trazas de $\mathrm{Cr}$ y Ni [ver Figura 3b].

Tabla 5.- Composición química de elementos mayoritarios de las piezas arqueológicas analizadas.

\begin{tabular}{|c|c|c|c|c|c|c|c|c|c|c|c|}
\hline Muestras & $\mathrm{SiO}_{2}$ & $\mathrm{Al}_{2} \mathbf{O}_{3}$ & $\mathrm{Fe}_{2} \mathbf{O}_{3}$ & $\mathbf{M n O}$ & $\mathbf{M g O}$ & $\mathrm{CaO}$ & $\mathrm{Na}_{2} \mathbf{O}$ & $\mathbf{K}_{2} \mathbf{O}$ & $\mathrm{TiO}_{2}$ & $\mathbf{P}_{2} \mathbf{O}_{5}$ & $\mathbf{S O}_{3}$ \\
\hline MSID_29 & 0.31 & 0.01 & 0.04 & 0.01 & 0.45 & 51.46 & 0.04 & 0.01 & 0.01 & 0.01 & 0.08 \\
\hline MSID_30 & 1.78 & 0.02 & 0.06 & 0.03 & 0.22 & 52.18 & 0.03 & 0.03 & 0.01 & 0.01 & 0.06 \\
\hline
\end{tabular}


Tabla 6.- Composición química de elementos traza de las piezas arqueológicas analizadas.

\begin{tabular}{l}
\begin{tabular}{|l|l|l|l|l|l|l|l|l|l|l|l|l|l|l|}
\hline Muestras & As & Ba & Cl & Co & Cr & Cu & Ga & Hf & La & Mo & Nb & Nd & Ni & Pb \\
\hline MSID_29 & 0,0 & 0,0 & 181,9 & 0,0 & 13,3 & 0,0 & 7,0 & 2,5 & 6,9 & 1,6 & 0,0 & 0,0 & 1,5 & 0 \\
\hline MSID_30 & 0,0 & 227,8 & 75,0 & 0,0 & 0,0 & 0,0 & 5,7 & 0,0 & 8,9 & 1,7 & 0,0 & 1,7 & 0,0 & 0 \\
\hline Muestras & Rb & Sc & Sm & Sr & Ta & Th & TI & V & U & W & Y & Yb & Zn & Zr \\
\hline MSID_29 & 7,4 & 18,7 & 3,4 & 173,9 & 0,0 & 0,0 & 0,8 & 0,0 & 0,0 & 0,0 & 12,3 & 1,9 & 51,0 & 0,0 \\
\hline MSID_30 & 8,7 & 17,9 & 3,5 & 268,5 & 0,0 & 0,5 & 0,8 & 0,0 & 0,0 & 5,5 & 12,7 & 1,4 & 47,5 & 0,0 \\
\hline
\end{tabular} \\
\hline
\end{tabular}
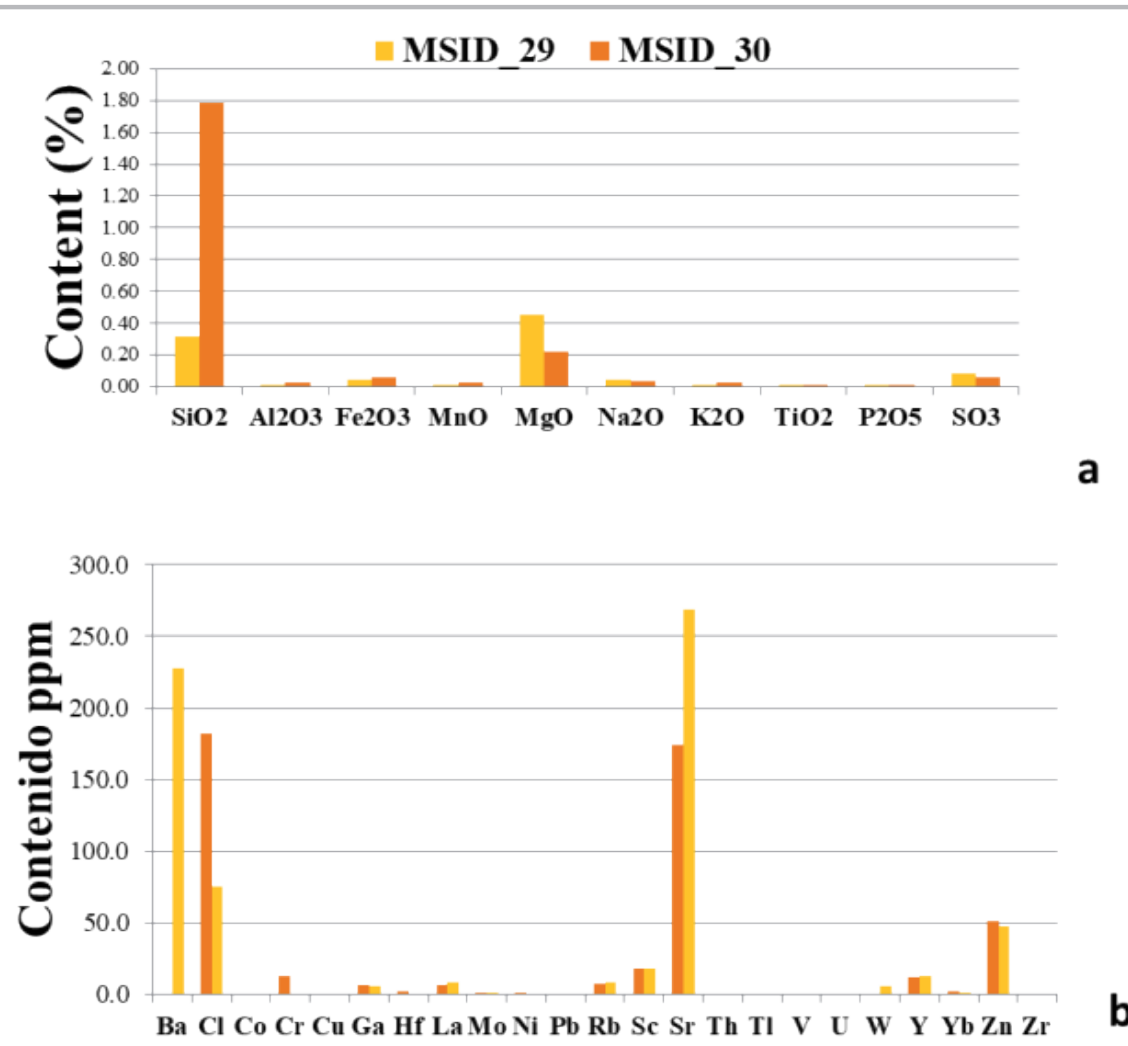

Figura 3.- a) Composición de elementos químicos mayoritarios de las muestras arqueológicas. b) Contenidos de elementos traza en las muestras arqueológicas.

Con base en los datos petrográficos y geoquímicos obtenidos del análisis de las piezas arqueológicas podemos concluir que en la elaboración de la escultura de Livia se han utilizado dos piezas de mármol con características diferentes desde el punto de vista textural en cuanto al tamaño de grano y diferencias en su composición química en cuanto al contenido en $\mathrm{SiO}_{2}$, $\mathrm{MgO}, \mathrm{Ba}, \mathrm{Cl}$ y Sr. Esto pone de manifiesto la selección cuidadosa del material para la elaboración de retratos en esculturas en época romana; generalmente uno más puro desde el punto de vista químico y a escala macroscopica se corresponde con un mármol de aspecto más traslucido y homogéneo.

Para atribuir a estos dos fragmentos la procedencia más probable, a continuación se establece un estudio comparativo de la composición química de elementos mayoritarios y traza con las muestras de Almadén de la
Plata, Borba y mármoles griegos e italianos recogidos en Arqueodata, IAPH (Ontiveros 2008; Ontiveros et al. 2012; Taylor 2015). Estos resultados también se contrastan con datos procedentes de fuentes documentales realizadas sobre mármoles foráneos como de Luni (Gorgoni et al. 2002; Lazzarini 2004; Cantisani et al. 2005; Lapuente et al. 2012; Paros (Gorgoni et al. 2002; Lazzarini 2004; Lapuente et al. 2012; Antonelli and Lazzarini 2015), Naxos (Gorgoni et al. 2002; Lazzarini 2004; Antonelli \& Lazzarini 2015) y de Estremoz (Taelman et al. 2013).

\section{-Mármol de la cabeza de Livia}

La composición química de elementos mayoritarios de los mármoles de Paros, Naxos y Almadén de la Plata se muestra en la Tabla 7. En el caso de los mármoles de Almadén del Plata, se han seleccionado tres muestras de cantera de 
Tabla 7.- Composición de elementos mayoritarios de las muestras de mármol blanco translúcido de Almadén de la Plata, Paros y Naxos (Arqueodata, IAPH).

\begin{tabular}{|l|l|l|l|l|l|l|l|l|l|l|l|}
\hline Muestras & $\mathrm{SiO}_{2}$ & $\mathrm{Al}_{2} \mathrm{O}_{3}$ & $\mathrm{Fe}_{2} \mathbf{O}_{3}$ & $\mathrm{MnO}$ & $\mathrm{MgO}$ & $\mathrm{CaO}$ & $\mathrm{Na}_{2} \mathbf{O}$ & $\mathrm{K}_{2} \mathrm{O}$ & $\mathrm{TiO}_{2}$ & $\mathbf{P}_{2} \mathrm{O}_{5}$ & $\mathbf{S O}_{3}$ \\
\hline ALD-8 & 1,76 & 0,24 & 0,07 & 0,02 & 1,09 & 52,65 & 0,03 & 0,13 & 0,01 & 0,04 & 0,02 \\
\hline ALD-40 & 0,83 & 0,07 & 0,05 & 0,01 & 0,43 & 54,64 & 0,05 & 0,04 & 0,01 & 0,01 & 0,01 \\
\hline ALD-41 & 1,08 & 0,08 & 0,04 & 0,01 & 0,38 & 54,62 & 0,03 & 0,05 & 0,01 & 0,01 & 0,01 \\
\hline Paros & 0 & 0 & 0,06 & 0 & 0,26 & 59,13 & 0,02 & 0 & 0 & 0,01 & 0,02 \\
\hline Naxos & 0,05 & 0,01 & 0,01 & 0,01 & 0,39 & 57,28 & 0,03 & 0,01 & 0,01 & 0,02 & 0,01 \\
\hline
\end{tabular}

rasgos petrográficos similares a la muestra MSD-29, dada la variedad textural y composicional observada en los distintos afloramientos de cantera. Los datos indican que los mármoles de Paros y Naxos contienen bajos contenidos en $\mathrm{Mn}$ coincidente con los resultados de Poretti (2016) $(<$ $8 \mathrm{ppm}$ ), valores similares a las muestras de Almadén de la Plata, así como su contenido en $\mathrm{P}_{2} \mathrm{O}_{5^{\prime}}$ y $\mathrm{SO}_{3}$.

La muestra MSD-29 presenta valores similares de $\mathrm{SiO}_{2}$ y $\mathrm{MgO}$ en el mismo rango de variación que el mármol de Almadén de la Plata. El contenido en $\mathrm{K} 2 \mathrm{O}$ (relacionado con su contenido en feldespatos) es más parecido al observado en el mármol de Paros y Naxos (pero en un margen muy discreto). Se destaca su mayor contenido en $\mathrm{SO}_{3}$ con respecto a las muestras de cantera; ello se puede relacionar con procesos de alteración durante el enterramiento de la pieza, ligados a la oxidación de pirita y la formación de manchas rojizas observadas en la totalidad de la cara de la escultura [ver Figura 4a].

Los datos de elementos trazas de estas variedades de mármol analizadas se muestran en la Tabla 8. Los datos indican cierta variabilidad en cuanto al contenido en elementos traza, dentro de las muestras de Almadén de la Plata; destacamos el contenido en $\mathrm{Sr}$ y $\mathrm{Cl}$, siendo la muestra ALD-8 la que presenta mayor contenido en $\mathrm{Sr}$ y ausencia de Ba. El mármol de Paros presenta bajo contenido en elementos traza, sin embargo, se detecta
$\mathrm{Cu}$ y $\mathrm{Pb}$, coincidente con los datos de Poretti (2016), no presentes en las muestras de Almadén de la Plata. La muestra de Naxos presenta valores similares de Sr con los de Almadén de la Plata ( $\mathrm{Sr}>182$ ppm), coincidente también con los datos de este último autor, con valores superiores al mármol de Paros.

Si comparamos estos datos con la muestra MSD-29 (mármol de la cabeza) observamos valores similares en el contenido $\mathrm{Ba}$, Sr, Y, Ga, y Zn con las muestras de Almadén de la Plata y Naxos y los contenidos en el $\mathrm{Cl}$ se asemejan más a los observados en Almadén de la Plata. Se destaca la presencia de Ni y ausencia de La y Zn en el mármol de Naxos, que no se observa en el resto de las muestras, y ausencia de La y $Z$ r, elementos que marcan diferencias de interés con el resto de las muestras de referencia, que sí están presentes en las muestras de Almadén de la Plata. Aunque el Zr se detecta también en Paros sus diferencias con respecto a otros elementos traza permiten atribuir a este mármol como posible origen Almadén de la Plata [Figura4b].

Con base en estos rasgos geoquímicos al mármol de la cabeza de Livia se le puede atribuir su origen en el mármol blanco translúcido de Almadén de la Plata o Naxos. Sin embargo, la presencia de La y contenido en $\mathrm{Cl}$ permite atribuirle como origen más probable la cantera bética de Almadén de la Plata.

Tabla 8.- Composición química de elementos traza de las muestras de mármol de Almadén de la Plata, Paros y Naxos (Arqueodata, IAPH).

\begin{tabular}{|c|c|c|c|c|c|c|c|c|c|c|c|c|c|c|}
\hline Muestras & As & $\mathrm{Ba}$ & $\mathrm{Cl}$ & Co & $\mathrm{Cr}$ & $\mathrm{Cu}$ & Ga & $\mathrm{Hf}$ & La & Mo & $\mathbf{N b}$ & Nd & $\mathrm{Ni}$ & $\mathbf{P b}$ \\
\hline ALD-8 & 5 & 1 & 23 & 0 & 25 & 0 & 5 & 0 & 2 & 2 & 0 & 22 & 9 & 0 \\
\hline$A L D-40$ & 4,7 & 14,1 & 112,7 & 2,5 & 0 & 0 & 4,1 & 3,4 & 15,4 & 2,1 & 0 & 6,7 & 0 & 0 \\
\hline$A L D-41$ & 0 & 30,1 & 69,3 & 2,2 & 0 & 0 & 4,5 & 4 & 16,9 & 2,1 & 0 & 5,3 & 0 & 0 \\
\hline Paros & 0 & 0 & 26 & 0 & 8 & 21 & 2 & 0 & 0 & 4 & 0 & 11 & 0 & 10 \\
\hline Naxos & 2 & 18 & 39 & 0 & 0 & 0 & 5 & 0 & 0 & 2 & 0 & 17 & 15 & 0 \\
\hline Muestras & $\mathbf{R b}$ & Sc & Sm & $\mathrm{Sr}$ & Ta & Th & TI & v & u & $\mathbf{w}$ & $\mathbf{Y}$ & $\mathbf{Y b}$ & $Z n$ & $\mathrm{Zr}$ \\
\hline ALD-8 & 5 & 25 & 2 & 254 & 0 & 0 & 0 & 0 & 0 & 0 & 11 & 1 & 15 & 3 \\
\hline$A L D-40$ & 3,9 & 18 & 2,5 & 152,9 & 0 & 0 & 0 & 2,1 & 0,5 & 1,6 & 10,8 & 2 & 49,3 & 0 \\
\hline$A L D-41$ & 2,2 & 18,8 & 2,6 & 165,6 & 0 & 0 & 0 & 3,9 & 0,5 & 10 & 10,6 & 2,2 & 50,3 & 2,4 \\
\hline Paros & 1 & 8 & 2 & 110 & 0 & 1 & 0 & 0 & 0 & 0 & 0 & 0 & 5 & 5 \\
\hline Naxos & 1 & 25 & 1 & 187 & 0 & 0 & 0 & 0 & 0 & 0 & 10 & 1 & 10 & 0 \\
\hline
\end{tabular}




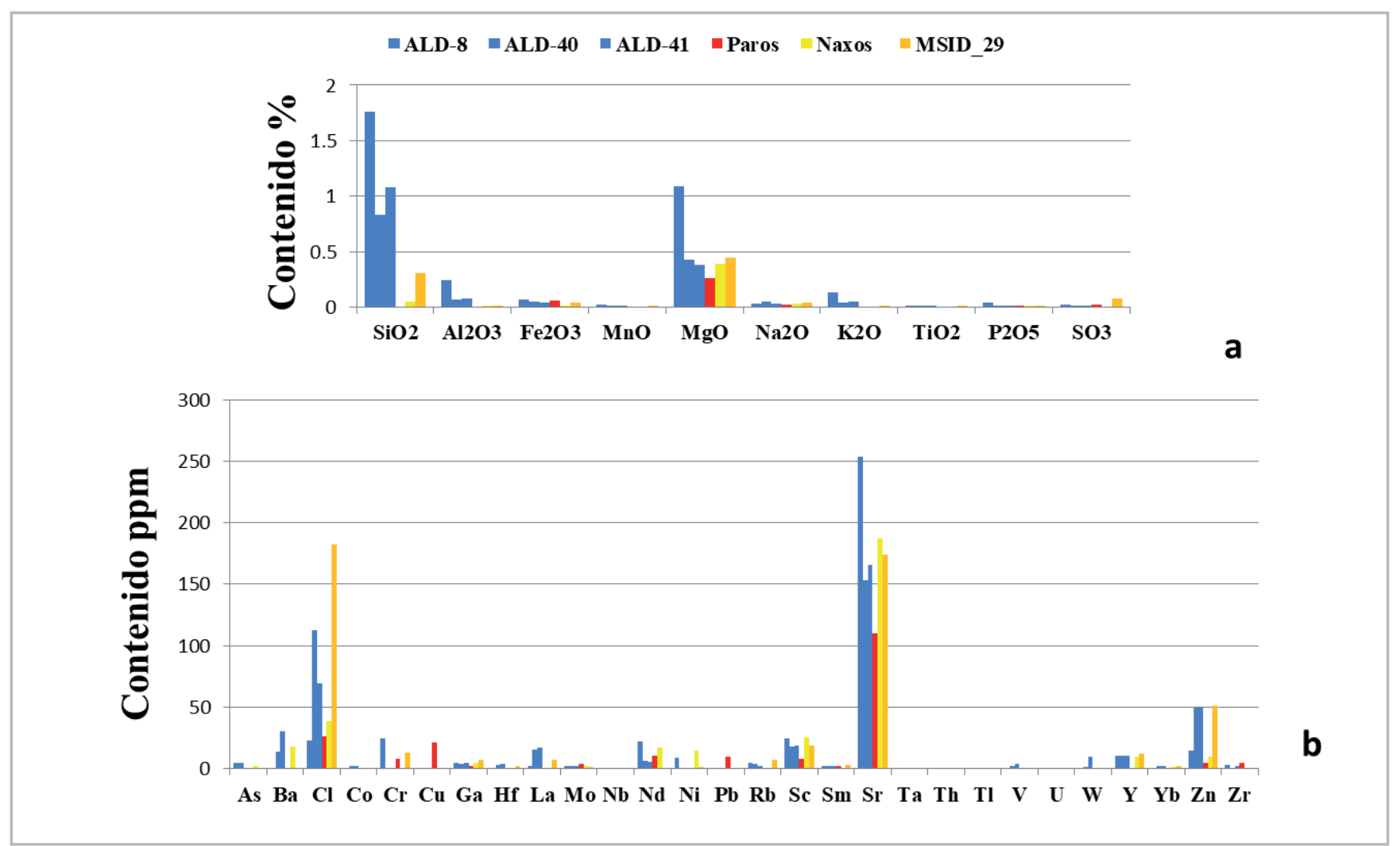

Figura 4.- a) Comparativa de elementos químicos mayoritarios de muestras de referencia con las muestras arqueológicas. b) Comparativa de elementos químicos traza de muestras de referencia con las muestras arqueológicas.

\section{-Mármol del cuerpo de Livia}

La composición química de elementos mayoritarios de las muestras seleccionadas de los mármoles de Borba, Almadén de la Plata y Luni de referencia se muestra en la Tabla 9. Los datos indican que la muestra de Almadén de la Plata presenta una composición similar a las variedades más puras del mármol de Borba. La comparación de estas variedades hispanas con la muestra MSD-30 indican valores similares en $\mathrm{Fe}_{2} \mathrm{O}_{3}$ y $\mathrm{MgO}$ con el mármol de Almadén, aunque el bajo contenido en $\mathrm{K}_{2 \mathrm{O}}$ y los valores en $\mathrm{SiO}_{2}$ observados en la pieza arqueológica están en el margen de variación observado en el mármol de Borba [ver Figura 5a]. Esos datos no descartan la posibilidad de que se trate del mármol de Borba. Sus valores de isotopos de $C$ y $O$ no presentan grandes diferencias [Antonelli \& Lapuente 2015: 405-425, Taelman et al. 2013: 2227-36]. Se destacan también las diferencias en su contenido en $\mathrm{MgO}$ y $\mathrm{MnO}$, que investigaciones previas indican menores valores de estos componentes químicos en el mármol portugués con respecto a Almadén de la Plata (Casal Moura et al. 2007; Lopes \& Martins 2015), que en nuestro caso tampoco difieren significativamente, aunque sí se observa un mayor contenido en la pieza arqueológica. Las variaciones en cuanto al contenido en $\mathrm{Al}_{2} \mathrm{O}_{3}$ y $\mathrm{K}_{2} \mathrm{O}$ que presenta la muestra MSD-30 con respecto al mármol de Almadén de la Plata, se explicarían por el tamaño de muestra analizada y el mayor contenido en $\mathrm{SO}_{3}$ como en el caso anterior por contaminación de la pieza durante el enterramiento.
Los datos de composición química del mármol de Luni indican que se trata de un mármol muy puro con menor contenido en $\mathrm{SiO}_{2}, \mathrm{Al}_{2} \mathrm{O}_{3}, \mathrm{Fe}_{2} \mathrm{O}_{3}$ y $\mathrm{K}_{2} \mathrm{O}$ que Borba, Almadén de la Plata y la muestra MSD-30, por el contrario, este mármol presenta mayores contenidos de $\mathrm{MgO}$, coincidente con los datos (0.04\%o $-0.065 \%$ o) recogidos en trabajos previos (Atanasio et al. 2015, Poretti 2016; Poretti et al. 2017, Wielgosz-Rondolino et al. 2020). Estos valores son superiores a otras variedades de mármol de grano fino del área mediterránea como el mármol Pentélico y el de Afyon (0.006-0.04 \% y 0.008-0.04\%o, respectivamente) o el mármol de Göktepe (Poretti et al. 2017; Wielgosz-Rondolino et al. 2020). Estos valores también son superiores al mármol de Almadén de la Plata, aunque similar a algunas muestras de Borba. El mármol de Luni también se caracteriza por bajos contenidos en Mn, (4.5 ppm), (Poretti 2016), valores similares a las muestras de Borba (Estremoz) y Almadén de la Plata que se analizan en este trabajo [ver Figura 5a].

Los datos de los elementos trazas de las muestras de los mármoles de Borba, Almadén de la Plata y Luni se muestran en la Tabla 10. Los resultados indican mayores contenidos en Ba para la muestra de Almadén de la Plata, similar a la muestra MSD-30, respecto a Borba, conforme con los trabajos de Taelman et al., (2013:2227-36). Sin embargo, se observa similitud en cuanto al contenido en Sr que difiere en ambos casos con los valores observados en la muestra MSD-30. Las muestras de mármol de Borba y MSD-30 presentan similitud en el contenido en $\mathrm{Cl}$ (no detectado en esta variedad de mármol de Almadén de la Plata) y Zn [ver Figura 5b]. 
Tabla 9.- Composición química de elementos mayoritarios de Borba, Almadén de la Plata y Luni (Arqueodata, IAPH).

\begin{tabular}{|c|c|c|c|c|c|c|c|c|c|c|c|}
\hline Muestras & $\mathrm{SiO}_{2}$ & $\mathrm{Al}_{2} \mathrm{O} 3$ & $\mathrm{Fe}_{2} \mathrm{O}_{3}$ & MnO & MgO & $\mathrm{CaO}$ & $\mathrm{Na}_{2} \mathrm{O}$ & $\mathrm{K}_{2} \mathrm{O}$ & $\mathrm{TiO}_{2}$ & $\mathrm{P}_{2} \mathrm{O}_{5}$ & $\mathrm{SO}_{3}$ \\
\hline P_BOR_02 & 0,78 & 0,21 & 0,09 & 0,01 & 0,23 & 54,29 & 0,05 & 0,09 & 0,01 & 0,01 & 0,01 \\
\hline P_BOR_03 & 0,17 & 0,27 & 0,11 & 0,01 & 0,51 & 53,69 & 0,05 & 0,15 & 0,02 & 0,01 & 0,01 \\
\hline P_BOR_04 & 1,45 & 0,45 & 0,17 & 0,01 & 0,3 & 54,61 & 0,04 & 0,22 & 0,02 & 0,01 & 0,03 \\
\hline P_BOR_05 & 2,1 & 0,67 & 0,2 & 0,01 & 0,4 & 52,77 & 0,04 & 0,4 & 0,03 & 0,01 & 0,02 \\
\hline$A L D_{-} 16$ & 1,59 & 0,27 & 0,07 & 0,01 & 0,28 & 54.40 & 0,03 & 0,33 & 0,02 & 0,01 & 0,01 \\
\hline$L-1$ & 0,17 & 0,03 & 0,02 & 0,01 & 0,40 & 54,86 & 0,03 & 0,02 & 0,01 & 0,03 & 0,03 \\
\hline$L-2$ & 0,18 & 0,06 & 0,05 & 0,01 & 0,46 & 54,64 & 0,03 & 0,04 & 0,01 & 0,03 & 0,03 \\
\hline L-3 & 0,25 & 0,06 & 0,02 & 0,01 & 0,43 & 55,21 & 0,04 & 0,03 & 0,02 & 0,04 & 0,04 \\
\hline
\end{tabular}

Tabla 10.- Elementos traza de las muestras del mármol de Borba y Almadén de la Plata (Arqueodata, IAPH).

\begin{tabular}{|l|l|l|l|l|l|l|l|l|l|l|l|l|l|l|}
\hline Muestras & $\mathbf{B a}$ & $\mathbf{C l}$ & $\mathbf{C o}$ & $\mathbf{C r}$ & $\mathbf{C u}$ & $\mathbf{G a}$ & $\mathbf{H f}$ & La & Mo & Nb & Nd & Ni & Pb & Rb \\
\hline P_BOR_01 & 9,8 & 76,3 & 2,2 & 0 & 0 & 5,5 & 3,5 & 18,1 & 2,2 & 0 & 5,5 & 2,6 & 0 & 3 \\
\hline P_BOR_02 & 0 & 76,4 & 0 & 0 & 0 & 5,2 & 3,7 & 14,9 & 2 & 0 & 6,7 & 0 & 0 & 1,8 \\
\hline P_BOR_03 & 86,6 & 99,6 & 3,9 & 0 & 0 & 6,8 & 3,7 & 15,9 & 2,4 & 0 & 7,5 & 3,1 & 0 & 5,5 \\
\hline P_BOR_04 & 7,5 & 68,8 & 4,4 & 0 & 0 & 3,4 & 3,9 & 10,8 & 2,1 & 0 & 5,2 & 0,4 & 0 & 3,2 \\
\hline ALD_16 & 82 & 0 & 0 & 0 & 0 & 6 & 0 & 16 & 2 & 0 & 17 & 3 & 0 & 5 \\
\hline L-1 & 14,9 & 83,2 & 0,5 & 0, & 0,0 & 5,4 & 4,3 & 1,2 & 1,6 & 0,0 & 8,1 & 4,7 & 4,2 & 2,4 \\
\hline L-2 & 0,0 & 78,9 & 0,0 & 0,0 & 0,0 & 7,4 & 4,0 & 17,4 & 1,7 & 0,0 & 2,5 & 0,0 & 0,0 & 5,2 \\
\hline L-3 & 12,3 & 88,8 & 0,0 & 0,0 & 0,0 & 6,2 & 4,1 & 5,9 & 1,8 & 0,0 & 9,3 & 0,4 & 0,6 & 6,5 \\
\hline
\end{tabular}

\begin{tabular}{|l|l|l|l|l|l|l|l|l|l|l|l|l|l|}
\hline Muestras & Sc & Sm & Sr & Ta & Th & TI & V & U & W & Y & Yb & Zn & Zr \\
\hline P_BOR_01 & 19,8 & 2,7 & 134,9 & 0 & 0 & 0 & 3,1 & 1,6 & 0 & 10,8 & 2,3 & 52,3 & 0,2 \\
\hline P_BOR_02 & 19,4 & 2,5 & 136,7 & 0 & 0 & 0 & 5,7 & 0,6 & 5,2 & 10,2 & 1,9 & 51,4 & 0 \\
\hline P_BOR_03 & 20,4 & 2 & 115,6 & 0 & 3,2 & 1,6 & 8,6 & 2,5 & 7,9 & 12,2 & 2,2 & 52,9 & 7,7 \\
\hline P_BOR_04 & 18,1 & 2,5 & 132 & 0 & 0 & 0 & 11,5 & 0,4 & 8,6 & 11,4 & 1,9 & 49,8 & 3,4 \\
\hline ALD_16 & 28 & 2 & 128 & 3 & 0 & 0 & 0 & 0 & 0 & 11 & 1 & 12 & 1 \\
\hline L-1 & 24,6 & 3,1 & 137,2 & 0,0 & 0,0 & 0,8 & 0,0 & 0,0 & 6,0 & 11,4 & 1,8 & 59,6 & 2,5 \\
\hline L-2 & 22,8 & 3,7 & 147,5 & 4,5 & 0,0 & 0,7 & 6,8 & 0,0 & 7,5 & 11,5 & 1,5 & 58,9 & 7,3 \\
\hline L-3 & 24,8 & 3,4 & 130,2 & 0,0 & 0,1 & 0,7 & 4,2 & 0,6 & 7,6 & 12,0 & 1,9 & 57,6 & 8,6 \\
\hline
\end{tabular}

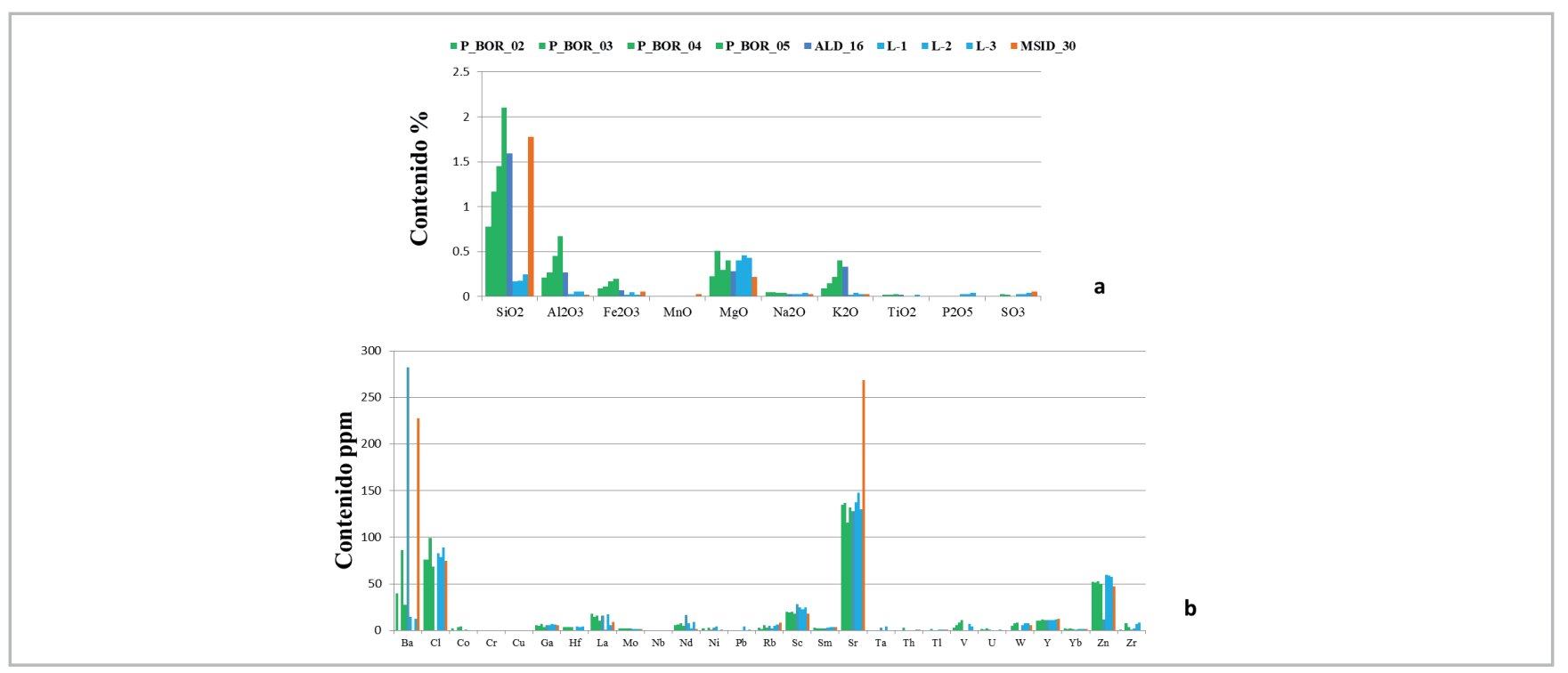

Figura 5.- a) Comparativa de componentes químicos mayoritarios de mármol Almadén de la Plata, Borba, Luni y la muestra MSD-30. b) Comparativa de componentes traza de Almadén de la Plata, Borba, Luni y la muestra MSD-30. 
Para el mármol de Luni, los datos indican valores similares al mármol de Borba en $\mathrm{Cl}, \mathrm{Zn}, \mathrm{V}$ y W y un menor contenido en $\mathrm{Ba}$ con respecto a la muestra de Almadén de la Plata y MSD-30. Se destaca la presencia de Th en una muestra de Luni, en las proporciones observadas por Poretti (2016), (>0.03 ppm), y Borba, elemento que no se ha detectado en Almadén de la Plata ni en la muestra MSD-30. Son por tanto el contenido en Ba y la presencia de Th los que permiten atribuir como origen más probable del mármol del cuerpo de la escultura también a las canteras de Almadén de la Plata.

\section{Conclusiones}

Las conclusiones de este trabajo se concretan en los siguientes puntos:

- Este estudio arqueométrico realizado sobre dos piezas pertenecientes a una escultura romana hallada en Asido ha tenido como objetivo identificar la procedencia de los materiales marmóreos usados en su elaboración.

- El estado semiacabado que presentan tanto el retrato como el cuerpo de la escultura de Livia de Asido, proyectada para una visión frontal, es un detalle propio de los talleres béticos que trabajaron en época julio-claudia en esa ciudad romana; era, por tanto, de interés poder confirmar esta hipótesis arqueológica apoyada sobre datos analíticos.

- El estudio ha puesto de manifiesto diferencias texturales y composicionales entre el mármol usado en la cabeza y en el cuerpo de la estatua de Livia, que se concretan en el mayor tamaño de grano, mayor pureza química y mayor contenido en $\mathrm{MgO}$ en el mármol de la cabeza y mayor heterogeneidad textural y mayor contenido en impurezas que presenta el mármol del cuerpo de la escultura, sobre todo en su contenido en $\mathrm{SiO}_{2}$.

- El estudio geoquímico comparativo del mármol de la cabeza (MSD-29) con mármoles foráneos como Paros o Naxos y algunas variedades hispanas similares encontradas en la Cantera de los Covachos, (Almadén de la Plata) indican contenidos en elementos químicos mayoritarios similares entre el mármol de la pieza arqueológica y las muestras de mármoles de referencia, aunque el contenido en $\mathrm{SiO}_{2}$ es superior en la canteras de Almadén de la Plata, mas similares a los observados en la pieza arqueológica. Respecto al contenido en elementos trazas, se destaca la presencia de $\mathrm{Cu}$ y $\mathrm{Pb}$ y el bajo contenido en Sr y demás elementos trazas que presenta el mármol de Paros con respecto a la muestra arqueológica, lo que hace establecer este origen como poco probable. Es la presencia de Ni en el mármol de Naxos y por otra parte el contenido en $\mathrm{Cl}$ y $\mathrm{Zn}$ que presenta el mármol de la pieza arqueológica lo que hace atribuir finalmente el origen de la pieza arqueológica a Almadén de la Plata.

- El estudio geoquímico comparativo del mármol del cuerpo de la Livia con mármoles hispanos como Borba
(Estremoz, Portugal) y Almadén de la Plata (Sevilla, España) o mármoles foráneos como Luni indica que el menor contenido en elementos mayoritarios y su alto contenido en $\mathrm{MgO}$ descarta su posible origen foráneo. Los contenidos en Ba que presentan Almadén de la Plata y la muestra MSD-30 respecto a Borba e incluso Luni hace atribuirle como origen más probable al mármol de Almadén de la Plata.

- En la elaboración de esta escultura de Livia localizada en la ciudad romana de Asido, como era habitual en otras zonas del Imperio romano, se seleccionaba de forma cuidadosa el mármol que se utilizaba para la elaboración de la cabeza/retrato con respecto al cuerpo, siendo piezas hechas aparte. Esto explica que el mármol de la cabeza corresponda a un mármol blanco más homogéneo desde el punto de vista textural, de aspecto translúcidoy ausencia de bandeados composicionales, como era propio de las esculturas elaboradas en época imperial. Para el caso del cuerpo se utilizó un mármol más opaco y heterogéneo, desde el punto de vista textural. Los veteados coloreados de la piedra eran disimulados por las capas pictóricas, que se aprecian a simple vista y que tenemos en estudio.

- La procedencia local de los mármoles de la estatua corrobora la hipótesis de que se trataba de una elaboración en un taller bético, posiblemente local, ya que se documenta la existencia de un taller de Asido desde época de Augusto.

\section{Agradecimientos}

Expresamos nuestro agradecimiento al anterior director del Museo de Cádiz, Dr. Juan Alonso de la Sierra, así como a la conservadora de esa institución, Dra. Dolores López de la Orden, por las facilidades otorgadas para el estudio de la escultura; asimismo, a D. Luis Carlos Zambrano, restaurador de la misma institución y responsable de la restauración de la estatua y del nuevo montaje museístico, por la extracción de las muestras analizadas ahora y por el apoyo prestado. Este trabajo se ha desarrollado y ha sido financiado en el marco de los Proyectos I+D+i del Ministerio de Economía y Competitividad de España HAR2013-42078-P y HAR201789004-P, de los que forman parte los autores.

\section{Referencias}

ÁlVAREZ PÉREZ, A., DOMÉNECH, A., LAPUENTE, P., PITARCH, A., ROYO, H. (2009). Mármoles y piedras de Hispania. Catálogo de la exposición, ICAC, Tarragona.

ANTONELLI, F., LAPUENTE, P., DASSANDIER D., KAMEL, S. (2014). "Petrographic characterization and provenance determination of the crystalline marbles used in the roman city of Banasa (Morocco): new data on the import of Iberian marble in roman North Africa", Archaeometry 57, 3: 405-425. https://doi. org/10.1111/arcm.12099. 
ANTONELLI, F.; LAZZARINI, L. (2015). "An updated petrographic and isotopic reference database for white marbles used in antiquity", Rend. Fis. Acc. Lincei, 26: 399-413. https://doi. org/10.1007/s12210-015-0423.

ATTANASIO D. (2003). Ancient white marbles: analysis and identification by paramagnetic resonance spectroscopy. L'Erma di Bretschneider, Roma.

ATTANASIO, D., BRUNO, M.; PROCHASKA, W., TAVUZ, A.B. (2013). "A Multi-Method Database of the Black and White Marbles of Göktepe (Aphrodisias), Including Isotopic, EPR, Trace and Petrographic Data". Archaeometry, 57, n 2 217-245. https://doi. org/10.1111/arcm.12076

BELFIORE, C. M, RICCA, M, LA RUSSA, M. F., RUFFOLO, S.A, GALLI G., BARCA, D., MALAGODI, M., VALLEFUOCO, M., SPROVIERI, M., PEZZINO, A. (2016). "Provenance study of building and statuary marbles from the Roman archaeological site of "Villa dei Quintili" (Rome, Italy). Ital. J. Geosci., 135, No. 2 (2016): 236-249. https:// doi.org/10.3301/IJG.2015.19

BELTRÁN FORTES, J. LOZA AZUAGA M. L. (2015). “La Livia de Asido (Medina Sidonia, Cádiz). Identificación de la estatua en el Museo de Cádiz", Madrider Mitteilungen, 56: 258-269.

BELTRÁN FORTES, J. LOZA AZUAGA M.L.., MONTAÑES CABALLERO S. (2018). Esculturas romanas de Asido (Medina Sidonia, Cádiz). Editorial UCA/ Universidad de Sevilla, Cádiz-Sevilla.

BELTRÁN FORTES, J., LOZA AZUAGA M. L. (2020). Provincia de Cádiz (Hispania Vlterior Baetica), Corpus de esculturas del Imperio Romano - España, I, 8, Cádiz-Tarragona: Editorial UCA / ICAC.

BLANC, P., LAPUENTE MERCADAL, M. P., GUTIÉRREZ GARCÍAMORENO, A. (2020). "A New Database of the Quantitative Cathodoluminescence of the Main Quarry Marbles Used in Antiquity". Minerals, 10, 381. https://doi.org/10.3390/min10040381

BLANCO, A. (1965). "Retratos de príncipes julio-claudios en la Bética", Boletín de la Real Academia de la Historia, 156(1): 89-100

BRILLI, M., LAPUENTE MERCADAL, M.P., GIUSTINI, F. ROYO PLUMED, H. (2020). Reply to Comments on the paper "Petrography and Mineralogy of the white marble and black stone of Göktepe (Muğla, Turkey) used in antiquity: New data for provenance determination" by M. Brilli, M.P. Lapuente Mercadal, F. Giustini and H. Royo Plumed (JAS Reports 2018, 19, 625-642). JAS Repor. Volumen 30, 10271. https://doi.org/10.1016/j.jasrep.2019.102071

CANTISANI E., FRATINI F., MALESANI P., MOLLI G. (2005). "Mineralogical and petrophysical characterization of white Apuan marble", Periodico di Mineralogia, 74 (2):117-140. EID: 2-s2.0-57649234042.

CAPEDRI, S., VENTURELLI, G., PHOTIDES, A. (2004). "Accesory minerals and $\delta 180 \delta 13$ marbles from Mediterranean area", Journal of Cultural Heritage, 5(1): 27-47. https://doi.org/10.1016/j. culher.2003.003
CAPEDRI, S., VENTURELLI, G. (2004). “Accessory minerals as tracers in the provenancing of archaeological marbles, used in combination with isotopic and petrographic data", Archaeometry, 46 (4): $517-$ 536. https://doi.org/10.1111/j.1475-4754.2004.00171.

CASAL MOURA, A. (2007). Mármores e Calcários Ornamentais de Portugal. Gestão de Artes Gráficas SA, Amadora.

CRAMER, T., MOLANO, J.C., DURAN ÖCAL, A. (2010). "Provenance determination of archaeological marbles as an example for the use of geoscientific methods in archaeometry", Geología Colombiana, 35:143-161. https://revistas.unal.edu.co/index.php/geocol/article/ view/27295

EBERT, A., GNOS, E., RAMSEYER, K., SPANDLER, C., FLEITMANN, D., BITZIOS, D. DECROUEZ, D. (2010). "Provenance of marbles from Naxos based on microstructural and geochemical characterization", Archaeometry 52(2): 209-228. https://doi.org/10.1111/j.14754754.2009.00477.x

FITTSCHEN, K. Y ZANKER, P. (1983). Katalog der römischen Porträts der Capitolinischen Museen und anderen kommunalen Sammlugen der Stadt Rom, I, Mainz am Rhein.

GARRIGUET, J. A. (2004). “Grupos estatuarios imperiales de la Bética: la evidencia escultórica y epigráfica". En Actas de la IV Reunión de Escultura romana en Hispania, T. Nogales y J. Gonçalves (coords.), Ministerio de Cultura, Madrid: 67-101.

GORGONI C., LAZZARINI L., PALLANTE P., TURI B. (2002). “An updated and detailed mineropetrographic and C-O stable isotopic reference database for the main Mediterranean marbles used in antiquity". En J.J. Herrmann, N. Herz \& R. Newman (eds.): ASMOSIA 5, Interdisciplinary Studies on Ancient Stone - Proceedings of the Fifth International Conference of the Association for the Study of Marble and Other Stones in Antiquity, June 1998, Archetype Publications, London:115-131. http://www.dst.uniroma1.it/riviste/permin/testi/ V73/39.pdf

LAPUENTE, M. P. (1995): Mineralogical, petrographical and geochemical characterization of white marbles from Hispania. En The Study of Marble and Other Stones Used in Antiquity, Y. Maniatis, N. Herz, Y. Basiakos, eds. Archetype Pub, London,151-160.

LAPUENTE, P., LEÓN, P., NOGALES,T., ROYO, H., PREITE MARTINEZ, M., BLANC, P.H. (2012). "White sculptural materials from Villa Adriana: study of provenance". En A. Gutiérrez Garcia, P. Lapuente and I. Rodà (ed.): Interdisciplinary studies on ancient stone: proceedings of the IX ASMOSIA Conference, Institut Català d'Arqueologia Clàssica Tarragona: $364-75$.

LAPUENTE, P., NOGALES-BASARRATE, T., ROYO, H., BRILLI, M., (2014). "White marble sculptures from the National Museum of RomanArt (Mérida, Spain): sources of local and imported marbles". European Journal of Mineralogy, 26: 333-54.

LAZZARINI, L., MOSCHINI, G., STIEVANO, B. M. (1980). "A contribution to the identification of Italian, Greek and Anatolian marbles through a petrological study and the evaluation 
of the Ca/Sr ratio". Archaeometry, 22: 173-183. https://doi. org/10.1111/j.1475-4754.1980.tb00940.x

LAZZARINI, L. (2004). "Archaeometric aspects of white and coloured marbles used in antiquity: the state of the art", Per. Mineral, 73:113-125.

LEÓN, P. (2001). Retratos romanos de la Bética, Junta de Andalucía, Sevilla.

LOPES, L., MARTINS, R. (2015). “Global Heritage Stone: Estremoz Marbles, Portugal". The Geological Society, London, 407: 57-74 https://doi.org/10.1144/SP407.10

MARIN, E., CLARIDGE, A., KOLEGA, M. Y RODÁ, I. (2004). “Livia d'Oxford-Opuzen". En E. Marin e I. Rodá (eds.): Divo Augusto. El descubrimiento de un templo romano en Croacia, University of Split: 76-86 y 340-344.

MOENS, L., ROOS, P., DE RUDDER, J., DE PAEPE, P., VAN HENDE, J., MARECHAL, R., WAELKENS, M. (1988). "A multi-method approach to the identification of white marbles used in antique artifacts". En N. Herz y M. Waelkens (ed.) Classical Marble: Geochemistry, Technology, Trade. NATO ASI Series (Series E: Applied Sciences), Springer, Dordrecht, 153: 243-250. https://doi.org/10.1007/97894-015-7795-3 27

ONTIVEROS ORTEGA, E. (2008). “Análisis Petrográfico de los Mármoles de la Cantera de los Castillejos y su Aportación al Estudio Arqueometríco de las Canteras Romanas de Almadén de la Plata, Sevilla". En T. Nogales y J. Beltrán (eds.), Marmora Hispania: Explotación y Uso de los Materiales Pétreos en la Hispania Romana. Roma, Italia. L'Erma di Bretschneider, vol. I: 365-376.

ONTIVEROS ORTEGA, E., BELTRAN FORTES, J., TAYLOR, R., RODRIGUEZ GUTIERREZ, O. (2012). “Petrography and Elemental Geochemistry of the Roman Quarries of los Castillejos and los Covachos (Almadén de la Plata, Seville, Spain). Outcrops and Semi-Elaborated Products". En A. Gutiérrez, P. Lapuente e I. Rodà (ed.), Interdisciplinary studies on ancient stone: proceedings of the IX ASMOSIA Conference, Institut Català d'Arqueologia Clàssica, Tarragona: 407-418.

PENSABENE, P. (2002). “Le principali cave di marmo bianco”. En M. de Nuccio y L. Ungaro (eds.), I marmi colorati della Roma Imperiale. Marsilio Editore, Venezia: 203-221.

PORETTI, G. (2016). "In situ analysis of white marble from the Mediterranean Basin by LA-ICP-MS: inferences on provenace based on trace-element profiles". Tesis doctoral de la Universidad La Sapienza, Roma. https://iris.uniroma1.it/ handle/11573/1158588 [ consulta: 20/02/2020].

PORETTI, G., BRILLI, M., DE VITO, C., CONTE, A.M., BORGHI, A., GÜNTHER, D., ZANETTI, A. (2017). "New considerations on trace elements for quarry provenance investigation of ancientwhite marbles". J. Cult. Herit. 28: 16 26. https://doi.org/10.1016/j. culher.2017.04.008
SCHOLZ, B. I. (1998). Untersuchungen zur Tracht der römischen Matrona. Bölhau Verlag, München.

TAELMAN, D., ELBURG, M., SMET, I., DE PAEPE, P., LOPES, L.., VANHAECKE, F., VERMEULEN, F. (2013). "Roman marble from Lusitania: petrographic and geochemical characterisation", Journal of Archaeological Science, 40(5): 2227-2236. https://doi. org/10.1016/j.jas.2012.12.030

TAYLOR, R. (2015). Las canteras romanas de mármol de Almadén de la Plata (Sevilla, España). Un análisis arqueológico. Tesis Doctoral, Universidad de Sevilla. https://idus.us.es/handle/11441/28214 [ consulta: 20/01/2020].

WIELGOSZ-RONDOLINO, D., ANTONELLI, F., BOJANOWSKI, M. J., GŁADKI, M., CEMAL GONCÜOGLU, M. \& LAZZARINI, L. (2020). "Improved methodology for identication of Goktepe white marble and the understanding of its use: A comparison with Carrara marble Dagmara". Journal of Archaeological Science, 113: 1-20. https://doi.org/10.1016/j.jas.105059

\section{Autor/es}

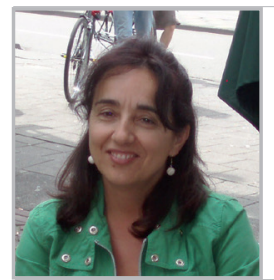

\section{Esther Ontiveros}

esther.ontiveros@juntadeandalucia.es Instituto Andaluz de Patrimonio Histórico.

Doctora en Ciencias Geológicas (1995) por la Universidad de Granada, con una tesis sobre morteros y tapial de época árabe. En 1996 comienza su actividad profesional en el Instituto Andaluz del Patrimonio Histórico (IAPH), en el marco del Programa de Normalización de Estudios Previos y Control de Calidad en la Intervenciones sobre Bienes Inmuebles, actividad que viene desarrollando en la actualidad. Dentro de las actividades de investigación desarrolladas en los últimos 25 años se destaca la línea de morteros de cal, tanto en el ámbito arqueométrico como de restauración, y el uso y explotación de materiales pétreos en el patrimonio andaluz. Es máster en Ciencia y Tecnología aplicada a la Conservación de Edificios Históricos (1992, Universidad de Granada) y Arquitectura y Patrimonio (2001, Universidad de Sevilla). Su producción científica en la actualidad incluye 35 capítulos de libro, 32 publicaciones en revistas, 46 aportaciones a congresos y 41 convenios y contratos.

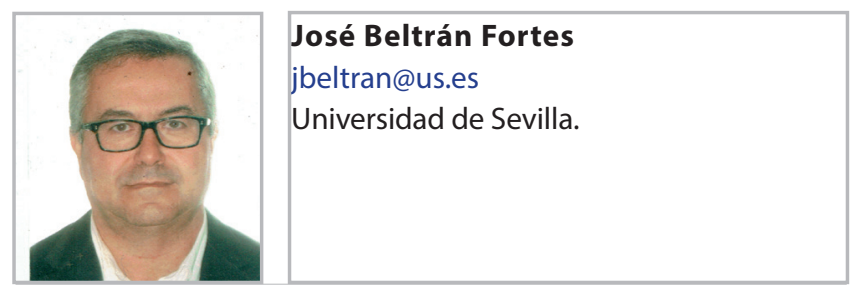

José Beltrán Fortes es Catedrático de Arqueología de la Universidad de Sevilla. Fue asimismo Profesor Titular de Arqueología en la Universidad de Córdoba. Actualmente es 
Director de la Editorial Universidad de Sevilla. Responsable del grupo de investigación "Historiografía y Patrimonio Andaluz" (del Plan Andaluz de Investigación), desde 1995 hasta hoy. Ha dirigido seis proyectos de I+D+i del Plan Nacional de Investigación, y en concreto, uno sobre el estudio arqueológico y arqueométrico de las canteras de mármol de la Bética y su explotación y uso en época romana. También ha coordinado algunos proyectos internacionales con Universidades de Italia y Portugal

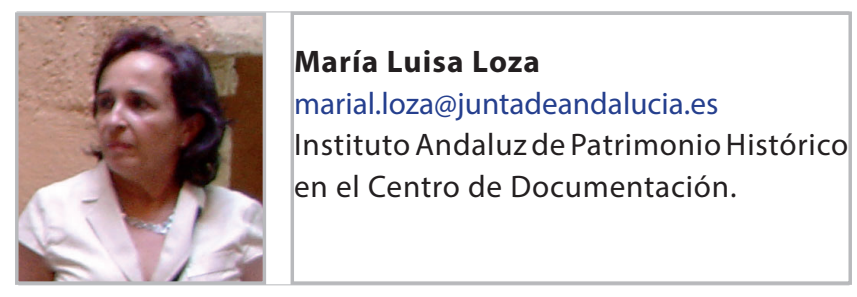

María Luisa Loza Azuaga es doctora en arqueología por la Universidad de Málaga (1992), postgrado en políticas culturales por la Universidad Pompeu i Fabra (1997) y Master en Arquitectura y Patrimonio por la Universidad de Sevilla (2007). Es conservadora del patrimonio histórico por oposición y en la actualidad trabaja en el Instituto Andaluz de Patrimonio Histórico en el Centro de Documentación. Ha participado en numerosos proyectos de I+D+i del Plan Nacional de Investigación y del PAIDI, centrándose en el estudio de las canteras de mármol así como de la escultura romana de la Bética. Es autora de cinco mongrafías, 16 colaboraciones en obras colectivas y un buen número de artículos y participaciones en congresos.

Artículo enviado el 14/04/2020 Artículo aceptado el 23/10/2020

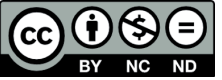

https://doi.org/10.37558/gec.v18i1.750 